\title{
SOBERANIA ECONÔMICA: OS INSTRUMENTOS DE EXERCÍCIO NA CONSTITUIÇÃO FEDERAL DE 1988, GLOBALIZAÇÃO E DESENVOLVIMENTO SUSTENTÁVEL
}

\author{
Hertha Urquiza Baracho ${ }^{1}$ \\ Wellington de Serpa Monteiro ${ }^{2}$
}

\begin{abstract}
RESUMO: Este trabalho tem por finalidade estudar sobre os instrumentos de soberania econômica previstos na Constituição Federal de 1988, como princípio da ordem econômica, que deve observar o desenvolvimento sustentável, objetivo de nosso Estado, levando em consideração as mudanças na soberania em face da globalização. Assim, aborda-se o princípio do desenvolvimento sustentável, a evolução do conceito de soberania, a globalização e suas consequências aos Estados nacionais e sua influência quanto à soberania econômica, bem como os principais instrumentos do exercício da soberania econômica constantes na $\mathrm{CRFB} / 1988$. A pesquisa foi feita por meio de revisão bibliográfica.
\end{abstract}

Palavras-chave: Desenvolvimento Sustentável; Globalização; Soberania Econômica.

\section{ECONOMIC SOVEREIGNTY: THE INSTRUMENTS OF OFFICE IN THE FEDERAL CONSTITUTION OF 1988, GLOBALIZATION AND SUSTAINABLE DEVELOPMENT}

\begin{abstract}
This work aims to study the instruments of economic sovereignty as provided for in the Federal Constitution of 1988, as principle of economic order, which must comply with the sustainable development goal of our State, taking into account of changes in sovereignty in the face of globalization. So, deals with the principle of sustainable development, the evolution of the concept of sovereignty, globalization and its consequences to the national States and your influence as economic sovereignty as well as the main instruments of economic sovereignty in 1988/CRFB constants. The survey was done through literature review.
\end{abstract}

Keywords: Sustainable Development; Globalization; Economic Sovereignty.

\footnotetext{
${ }^{1}$ Pós-doutorado na Università degli Studi di Firenzi, UNIFI, na área das Ciências Sociais Aplicadas. Doutora em Direito do Estado (Área concentração Direito Constitucional) pela PUC/SP. Mestre em Direito do Estado (Área de concentração Direito Constitucional) pela PUC/SP. Professora do Centro Universitário de João Pessoa UNIPÊ. Coordenadora do Grupo de Pesquisa: Relações Empresariais: função social e responsabilidade Social das empresas. End.: Rua Juiz Amaro Bezerra, 360, apto 501, Cabo Branco, João Pessoa (PB), CEP 58.045-070. Email: herthaurquiza@gmail.com

${ }^{2}$ Mestrando em Direito e Desenvolvimento pelo UNIPÊ. Especialista em Direito Público com Capacitação para o Ensino Superior (Faculdade Damásio). Especialista em Direito Processual (UNAMA/PA). Procurador da Fazenda Nacional. End.: Rua Maria de Lourdes Coutinho Torres, 34, apto 1302, Altiplano, João Pessoa (PB), CEP 58.046-170. Email: wserpa.wsm@gmail.com
} 


\section{INTRODUÇÃO}

O desenvolvimento sustentável está presente em nossa Constituição, como princípio norteador do mesmo, advindo dos objetivos do Estado brasileiro elencados no art. $3^{\circ}$ da CRFB/1988, notadamente o desenvolvimento nacional (art. $3^{\circ}$, II) e a erradicação da pobreza e a redução das desigualdades sociais e regionais ( $\operatorname{art.} 3^{\circ}$, III), combinado com a defesa do meio ambiente, que, além de ser um dos princípios da ordem econômica (art. 170, VI), é tratada de forma específica no art. 225 da mesma ${ }^{3}$.

Já a soberania, além de princípio básico do Estado brasileiro criado pela Constituição Federal de 1988 (art. $1^{\circ}$ ), também se manifesta como princípio da ordem econômica prevista em nossa Carta Política, conforme o teor no art. 170, I, aduz:

\footnotetext{
Art. 170. A ordem econômica, fundada na valorização do trabalho humano e na livre iniciativa, tem por fim assegurar a todos existência digna, conforme os ditames da justiça social, observados os seguintes princípios:

I - soberania nacional;
}

Frente a essa realidade constitucional, existe o nosso contexto mundial, marcado pela globalização, definida por Habermas (2001, p. 84) como um processo atual em que se intensificam as "relações de troca, de comunicação e de trânsito para além das fronteiras nacionais".

Esse fenômeno, no que tange ao seu aspecto ligado à economia - globalização econômica - exerce influência na lógica de produção, uma vez que desloca competências que eram dos Estados nacionais para o âmbito de empresas transnacionais e de órgãos supranacionais.

Assim, no contexto da globalização e, consequentemente, com o aumento da circulação de capitais, bens e tecnologia que deram origem à transnacionalização dos meios de produção e das relações entre os Estados nacionais é que devem ser abordados os mecanismos de exercício da soberania econômica previstos em nossa Constituição, que visam ao desenvolvimento nacional sustentável, pois essa é a realidade em que nos encontramos inseridos.

Pretende-se com o presente discutir a soberania econômica face ao fenômeno da

\footnotetext{
${ }^{3}$ Art. 225. Todos têm direito ao meio ambiente ecologicamente equilibrado, bem de uso comum do povo e essencial à sadia qualidade de vida, impondo-se ao Poder Público e à coletividade o dever de defendê-lo e preserválo para as presentes e futuras gerações.
} 
globalização, soberania esta que deve visar ao desenvolvimento nacional sustentável, como princípio dirigente presente em nossa Constituição, bem como os instrumentos do exercício da soberania econômica previstos na CRFB/1988, que objetivam esse desenvolvimento sustentável.

Para tanto, se faz necessário discutir o princípio do desenvolvimento sustentável, a soberania, o fenômeno da globalização e suas consequências, para que se possa compreender como a soberania econômica nacional foi atingida por esse processo, e os meios que nossa Constituição estipula para efetivá-la, levando em conta o objetivo de desenvolvimento nacional sustentável.

\section{PRINCÍPIO DO DESENVOLVIMENTO SUSTENTÁVEL}

No ordenamento, os princípios têm a função de organizar o sistema jurídico, atuando como elo responsável por demonstrar os resultados escolhidos pela nação, sendo inegável seu caráter prevalentemente axiológico. Daí a razão pela qual os valores atuais de uma nação determinam a real extensão e interpretação dos princípios.

Por outro lado, os princípios estão consubstanciados, de algum modo, em normas jurídicas, porque se não estiverem assim dispostos não terão relevância ou importância para o direito.

Como normas, os princípios orientam a correta aplicação das regras hierarquicamente inferiores, exercendo uma função criativa na exata medida em que impõem ao legislador a necessidade de criação de novas regras que venham a complementar o sistema em que estão inseridas. Por conseguinte, os princípios são o ponto de partida ou a regra mestra para a correta interpretação do sistema jurídico (ÁVILA, 2008, p.34).

$\mathrm{Na}$ Constituição Federal de 1988 figuram diversos princípios espalhados em suas normas, sendo que os princípios, que outrora percorreram o caminho do jus naturalismo, onde era inicialmente definido como conjunto de verdades objetivas derivadas da lei divina, posteriormente entrou na fase do positivismo jurídico (BONAVIDES, 1996, p. 261).

Em realidade, por um tempo, se considerou que os princípios não serviam para imposição a terceiros, portanto, desprovidos de força normativa. Na fase de positivismo jurídico, eles se fixam no ordenamento jurídico como alicerce do mesmo, vale dizer, como base e colunas do "edifício jurídico" (DANTAS, 2012, p. 131).

As Constituições elaboradas após o final da Primeira Guerra mundial têm algumas

Rev. de Direito, Economia e Desenvolvimento Sustentável| e-ISSN: 2526-0057| Porto Alegre | v. 4 | n. 2 | p. 93 - 114 | Jul/Dez. 
características comuns, dentre as quais, a declaração, ao lado dos tradicionais direitos individuais, dos chamados direitos sociais ou prestacionais, ligados ao princípio da igualdade material, que dependem de prestações diretas ou indiretas do Estado para serem usufruídos pelos cidadãos. Estas novas Constituições são consideradas parte do novo "constitucionalismo social" que se estabelece em boa parte dos Estados europeus e em alguns americanos (BERCOVICI, 2005, p. 11).

No caso de nossa Constituição, além de constituir o Brasil como um Estado Democrático de Direito (artigo $1^{\circ}$, caput), em seu artigo $3^{\circ}$ estipulou os objetivos do mesmo: construção de uma sociedade livre, justa e solidária; garantia do desenvolvimento nacional; erradicação da pobreza e da marginalização; redução das desigualdades sociais e regionais e promoção do bem de todos, sem quaisquer preconceitos discriminatórios.

É a primeira vez que uma Constituição nacional assinalou especificamente os objetivos do Estado brasileiro, logicamente não todos, mas os fundamentais e, entre eles, uns que valem como base das prestações positivas que venham a concretizar a democracia econômica, social e cultural, a fim de efetivar na prática o princípio da dignidade da pessoa humana (SILVA, 2007, p. 96).

Para tal finalidade, e por sua importância, a Constituição Federal trata diretamente da ordem econômica, ou seja, da ordem jurídica da economia, estipulando seus objetivos e princípios no artigo 170, caracterizando o seu caráter dirigente por determinar os objetivos, os programas e os fins a serem buscados não somente pelo Estado, mas também pela sociedade como um todo no aspecto econômico, uma vez que o "mercado" é, para além do aspecto econômico, uma instituição jurídica constituída pelo Direito Positivo do Estado moderno (GRAU, 2017, p. 32).

É tão importante reconhecer o papel crucial da riqueza, e disso se fala quando se trata de economia, na determinação de nossas condições e qualidade de vida, quanto a entender a natureza restrita e dependente dessa relação. Uma concepção adequada de desenvolvimento deve ir muito além da acumulação de riqueza e do crescimento do Produto Nacional Bruto e de outras variáveis relacionadas à renda. Sem desconsiderar a importância do crescimento econômico, precisamos enxergar muito além dele. (SEN, 2013, p. 28)

Ao consagrar uma economia de mercado, uma vez que nossa Constituição fundamenta a ordem econômica no trabalho e na livre iniciativa privada (art. 170 caput), fica estabelecido que, para o exercício da atividade econômica, devem certos princípios ser 
observados, dentre os quais figura a soberania nacional e a devida proteção e defesa do meio ambiente. Este último, como uma das marcas distintivas do desenvolvimento econômico sustentável, demonstra a necessária observância dos direitos de $3^{\text {a }}$ dimensão ou geração, ou seja, de dar uma marca solidária ao desenvolvimento, como necessário compromisso do Estado, criado por nossa Constituição, com o princípio da dignidade da pessoa humana, sendo este, inclusive, um dos fundamentos de nosso Estado (art. $1^{\circ}$, III da CRFB/1988), o qual, ao lado do direito à vida (art. $5^{\circ}$ caput), constitui o núcleo essencial dos direitos humanos (GRAU, 2017, p. 191).

Pela mesma razão, o crescimento econômico não pode ser considerado um fim em si mesmo. O desenvolvimento tem de estar relacionado, sobretudo, com a melhora da qualidade de vida que levamos e das liberdades de que desfrutamos. Assim, deve visar à expansão das "capacidades" das pessoas de levar o tipo de vida que elas valorizam. Essas capacidades podem ser aumentadas pelas políticas públicas, mas também, por outro lado, a direção da política pública pode ser influenciada pelo uso efetivo das capacidades participativas do mesmo povo (SEN, 2013, p. 33). No ensino de Veiga:

\footnotetext{
Assim entendida, talvez não haja noção que mais concentre a utopia da sociedade moderna do que a noção de desenvolvimento. De Marx a Hayek, passando por todas as nuances socialistas e liberais, dificilmente se encontrará uma esperança mais consensual do que o desenvolvimento (2004, p. 193).
}

É certo, todavia, que os conceitos de desenvolvimento social e desenvolvimento econômico não são exatamente sinônimos, mas o primeiro consubstancia algo muito mais amplo, fazendo referência a diversos fatores que compõem a vida em sociedade, como conceito multidisciplinar, que abarca o meio biológico e social, ao passo que o segundo se refere mais à ideia de geração de riqueza. $\mathrm{O}$ desenvolvimento econômico deve perseguir o desenvolvimento social; este deve absorver e orientar o desenvolvimento econômico, diante da necessidade de garantir dignidade de sobrevivência para todos (PONTES, 2012, p. 246).

Aqui cabe salientar a importância da noção de sustentabilidade, pois a sociedade atual deve evitar tudo o que possa ocorrer em prejuízo de seus descendentes. Vale dizer, pode a geração atual utilizar os recursos naturais, até por necessitar dos mesmos, mas sem desperdiçalos ou abusar do seu uso, a ponto de nada ou muito pouco ficar para as gerações futuras, que necessitarão também dos mesmos, como, por simples exemplos, o ar, a água e o solo. Não apenas nossos descendentes mais diretos, mas também os mais distantes, uma vez que quaisquer elementos da biosfera podem ser afetados pelo processo produtivo e pelo progresso, 
que dependem, fundamentalmente, de três ingredientes básicos: trabalho humano, capital produzido e recursos naturais (VEIGA, 2005, p. 122-123).

Um aspecto da globalização, de que trataremos com maior precisão no tópico a seguir, que é diretamente relacionado ao desenvolvimento sustentável, é o reconhecimento do caráter planetário da apreensão sobre a decadência ambiental mundial. E não é por outra razão que os movimentos ambientalistas são os que mais questionam (e até desafiam) a manutenção do EstadoNação como principal lócus de legitimidade do poder. O desgaste da camada de ozônio, o aumento do efeito estufa e as perdas de biodiversidade são problemas globais em sua própria gênese e âmago. São três questões que explicitam o cerne dos conflitos sociais sobre a sustentabilidade. (VEIGA, 2005, p. 146).

A Constituição Federal de 1988 trata de forma direta a questão do meio ambiente, fruto também da influência internacional crescente em relação a esse tema, como, por exemplo, da Conferência da ONU em Estocolmo de 1972 (Conferência das Nações Unidas sobre o Meio Ambiente Humano), e nas Constituições portuguesa de 1976 (art. 66) e espanhola de 1978 (arts. 45 e 46). Uma grande inovação trazida por nossa atual Constituição foi a inserção de um conteúdo humano e social no direito ao meio ambiente, deixando de considerar o mesmo do ponto de vista puramente patrimonial, mas vendo-o como direito de terceira dimensão, ou seja, de caráter meta-individual, sendo bem de uso comum do povo, cuja titularidade abrange a atual e as futuras gerações (SARLET, 2017, p. 44).

Nessa seara, portanto, se observa que nosso legislador constituinte originário demonstrou genuína preocupação em garantir que o desenvolvimento econômico nacional se dê não só pelo aspecto quantitativo (mero crescimento), mas, principalmente, qualitativo, em que "o desenvolvimento pode ser visto como um processo de expansão das liberdades reais que as pessoas desfrutam" (SEN, 2000, p. 17), dando ao Estado criado pela Constituição Federal de 1988 uma verdadeira característica de "Estado Socioambiental", conforme lição de Sarlet (2017, p. 43):

O Estado Socioambiental aponta para a compatibilidade da atividade econômica com a ideia de desenvolvimento (e não apenas crescimento) sustentável, de modo que a "mão invisível" do mercado seja substituída necessariamente pela "mão visível" do Direito.

Em que pese à preferência, em geral, apontar para a terminologia "Estado Ambiental" aqui se escolheu a nomenclatura "Estado Socioambiental", uma vez que entendemos ser 
necessária e urgente a convergência das agendas social e ambiental, num projeto jurídicopolítico para o desenvolvimento humano (SARLET, 2017, p. 38-39).

Assim, devemos ver nossa Carta Política como expressão de um Estado "Socioambiental", cuja Constituição estabeleceu, inclusive, os objetivos a serem buscados pelo mesmo (artigo $3^{\circ}$ ), o que permite compreensão dinâmica da Constituição, com possibilidade de abertura do texto constitucional para desenvolvimentos futuros (BERCOVICI, 2011, p. 208-209).

Esse nosso Estado Socioambiental, previsto e tratado em nossa Carta Política, destarte, tem como marca seu comprometimento com o desenvolvimento sustentável, o qual se firma em cinco pilares: social, econômico, ambiental, territorial e político.

No que tange ao social, fundamental por motivos tanto intrínsecos quanto instrumentais, a fim de minorar as profundas desigualdades e a disrupção social que paira na sociedade de nosso país; o econômico, sendo a real viabilidade econômica a conditio sine qua non para que as coisas ocorram; o ambiental, nas suas duas dimensões - os sistemas de sustentação da vida como provedores dos recursos, bem como os "recipientes" para a acomodação dos "resíduos" produzidos pela sociedade; o territorial, relacionado à disposição espacial dos recursos, das populações e das atividades, que devem buscar maior capilaridade e racionalidade e, por fim, o político, onde a governança democrática é um valor fundador necessário para fazer que as coisas realmente aconteçam, ou seja, as verdadeiras aspirações da sociedade possam ser ouvidas e priorizadas como um todo (SACHS, 2004, p. 17).

O processo de desenvolvimento, quando julgado pela ampliação da liberdade humana precisa incluir a eliminação de privação da liberdade. Mesmo se ela não tivesse interesse imediato em exercer a liberdade de expressão ou de participação, por exemplo, ainda assim seria uma privação de suas liberdades se ela não pudesse ter escolha nessas questões. Deve ficar claro que a visão de liberdade envolve tanto os processos que permitem a liberdade de ações e decisões como as oportunidades reais que as pessoas têm, dadas as suas circunstâncias pessoais e sociais (SEN, 2013, p. 56).

Assim, nosso Estado deve, obrigatoriamente, mediante os seus instrumentos, buscar o desenvolvimento sustentável, caracterizado por uma eficiência que seja, ao mesmo tempo, alocadora (econômica), includente (social) e ecoeficiente, ou seja, preocupada com a preservação do meio ambiente, para a atual e para as futuras gerações. (SACHS, 2004, p. 42). 


\section{SOBERANIA ECONÔMICA E GLOBALIZAÇÃO}

Para o presente trabalho é importante se compreender o conceito de soberania e seu desenvolvimento, frente aos aspectos da globalização, pois esse conceito é necessário para, depois, podermos falar dos instrumentos de soberania econômica previstos na Constituição Federal de 1988.

O debate em torno do conceito de soberania evoca a lição de ser a soberania "o poder absoluto e perpétuo de uma República" (BODIN, 2011, p. 195). Com base no conceito formulado supra, pode-se afirmar que a soberania se impõe em dois planos - no plano interno e no plano externo. No primeiro, a soberania diz respeito às relações que ocorrem dentro do território do Estado, em que a vontade deste deve prevalecer, ou seja, ser suprema. No segundo, a soberania diz respeito às relações que ocorrem fora do território do Estado, ou seja, diz respeito às relações com outros Estados soberanos (BARROSO, 2001, p. 32).

A titularidade da soberania é do Estado, que por meio dela exerce superioridade em face de qualquer outro poder, tendo como atributos o direito de dar leis a todos em geral e a cada um em particular, de declarar a guerra e negociar a paz, de nomear os principais magistrados e funcionários, de decidir em última instância e de conceder graça aos condenados, de cunhar moedas e estabelecer pesos e medidas e, finalmente, de gravar os súditos com impostos e contribuições. Soberania é, portanto, a vontade individual ou coletiva do próprio Estado enquanto pessoa jurídica (LEWANDOWSKI, 2004, p. 231).

Segundo Barroso, no entanto, ao longo de toda a história ocidental a "vontade do Estado" mudou de titularidade:

Com Jean Bodin e Hobbes, a soberania tem seu centro de gravidade no monarca. Com Locke e a Revolução Inglesa, ela se transfere para o Parlamento. Com Rousseau e as Revoluções Francesa e Americana, o poder soberano passa nominalmente para o povo, uma abstração aristocrático- burguesa que, com o tempo, iria democratizarse. (BARROSO, 2011, p. 31-32)

A intergovernabilidade é o modo pelo qual os Estados tradicionalmente se relacionam entre si e com os organismos internacionais no plano internacional. No âmbito desse sistema de cooperação, as decisões devem ser tomadas por unanimidade ou por consenso com a presença de todos os membros. Não há a criação de um direito superior ao nacional e não existe vinculação direta dos Estados com seus cidadãos, existe a necessidade de processo de 
internalização dessas normas (RAYMUNDO, 2003, p. 164-165).

Do ponto de vista político ou sociológico, é possível afirmar que a soberania pertence ao povo ou à nação, inclusive nossa própria Constituição afirma que todo o poder emana do povo (art. $1^{\circ}$, parágrafo único), mas, do ponto de vista jurídico, ela só pode ser exercida pelo Estado, concluindo-se que a soberania do povo ou da nação é a mesma do Estado, apresentando, porém, em relação ao Estado, caráter jurídico (REALE, 1984, p. 153-154). Em suma:

\begin{abstract}
Soberania é um atributo essencial do Estado, sendo conceito de dupla significação: do ponto de vista do direito internacional, expressa a ideia de igualdade, de não subordinação; do ponto de vista interno traduz a supremacia da Constituição e da lei interna, e da superioridade jurídica do Poder Público na sua interpretação e aplicação. (BARROSO, 2001, p. 192)
\end{abstract}

Conquanto os sentidos internos e externos sejam os mais comuns quando se trata de soberania, não é a única forma de ver os sentidos do conceito de soberania, pois, se pode dar uma classificação diferente advindo de sua dualidade: ora se fala de soberania como o efetivo poder de um Estado - soberania descritiva, que permite o funcionamento dos aparelhos estatais; ora da qual advêm os limites desse poder, ou seja, uma teoria normativa negativa da soberania, pois esta é limitada tanto internamente, em face dos direitos fundamentais, quanto externamente, em virtude dos limites legítimos de intervenção em Estados soberanos, advogando as restrições das competências estatais (COSTA, 2004, p. 42).

Convém lembrar que é possível também uma teoria normativa positiva da soberania, relativa aos aspectos que por ela devem ser implementados. Aqui fica a lição de Canotilho (2003, p. 1275):

\footnotetext{
Se ontem a 'conquista territorial', a 'colonização', o 'espaço vital', o 'interesse nacional', a 'razão de estado' surgiam sempre como categorias quase ontológicas, hoje os fins dos Estados podem e devem ser os da construção de 'Estados de Direito democráticos, sociais e ambientais', no plano interno, e Estados abertos e internacionalmente amigos e cooperativos no plano externo.
}

Entretanto, com o advento da globalização, a defesa do Estado-nação já não traz a manutenção da velha ideia de soberania, mas sim um novo conceito, onde o Estado-nação não é mais vistos com poderes absolutos dentro de seu território, mas percebido como local a partir de novas formas de governabilidade. Em suma: o Estado-nação continua sendo fundamental, mas não mais como poder governante e sim como uma classe de poderes e agências políticas, em um sistema de poder complexo, dos níveis mundiais aos locais, com grande importância, haja vista sua relação com o território e a população locais (GONÇALVES, 2004, p. 25-26). 
A importância de se entender o sentido da soberania econômica, encontra-se assim, aumentada. Embora possam ser dados vários conceitos sobre a soberania econômica, pode esta ser definida como a autodeterminação de um Estado em sua política econômica, caracterizando uma independência das decisões econômicas (LAFAYETTE, 2005, p. 190).

Prevista no já transcrito artigo 170, I de nossa Constituição Federal, sua previsão constitucional parece demonstrar a previsão do constituinte da abertura de mercados, amplificada pela queda do Muro de Berlim, o fim da União Soviética e do bloco comunista, incrementada pelos abrandamentos alfandegários, a eliminação do xenofobismo, a questão da livre circulação dos capitais flutuantes e o estabelecimento das linhas de produção mundiais, traços característicos de um processo de maximização da rentabilidade econômica, com uma profunda alteração do mundo capitalista em que estamos inseridos (LAFAYETTE, 2005, p. 194).

Portanto, foi na década de noventa do século XX, com o fim da guerra fria, que o capitalismo se consolidou como único sistema econômico e que se caracteriza, atualmente, por um grande movimento de capitais, mais até do que de mercadorias e pessoas. O capital, para muitos, não tem nacionalidade, mas sim interesses de maior acúmulo e expansão, e essa desnacionalização do capital é que determinou ao fenômeno da globalização, a criação de novas desigualdades internacionais (KIERECZ, 2015, p. 988).

Há uma dupla visão sobre a globalização: de um lado estão os que enxergam a mesma como um fenômeno real e que melhor sintetiza a condição humana contemporânea, ou seja, uma visão mais otimista do fenômeno da globalização; de outro lado, temos os que são intitulados de "céticos", para quem se caracterizaria mais como uma "ilusão" inflada pelo entusiasmo de globalistas. Estes demostram a crescente importância de problemas mundiais que engendram cada vez mais consciência sobre o destino comum da humanidade, enquanto os melhores céticos alertam para a contínua primazia de interesses nacionais e de fatos culturais que dão sentido às identidades sociais e territoriais (VEIGA, 2005, p. 143).

Podemos, portanto, dizer que ambas as visões sobre a globalização, tanto os otimistas (globalistas) quanto os céticos tendem a convergir sobre cinco aspectos da mesma: 1) maior interligação econômica nas e entre regiões do mundo, ainda que com conseqüências multifacetadas; 2) novas desigualdades e abalo de velhas hierarquias, provocadas pela competição inter-regional; 3) ampliação de problemas transnacionais e transfronteiriços (como lavagem de dinheiro ou disseminação de organismos geneticamente modificados, os OGMs); 4) expansão das formas de gestão internacional — como a União Europeia e a Organização Mundial do Comércio 
(OMC) -, que traz novas interrogações sobre o tipo de ordem mundial a ser construída; 5) exigência de novas maneiras de pensar e de dar respostas criativas sobre as futuras formas democráticas de regulação política. (VEIGA, 2005, p. 144).

Para José Eduardo Faria, a globalização assume a configuração de "uma interação de natureza sistêmica, acima de tudo alicerçada na especialização e mercantilização do conhecimento, na eficiência, na tecnologia, na competitividade, na produtividade e no dinheiro" (FARIA, 2004, p. 52-53). Ainda segundo o mesmo Faria, decorre da globalização:

\begin{abstract}
(...) a crescente autonomia adquirida pela economia em relação à política; a emergência de novas estruturas decisórias operando em tempo real e com alcance planetário; as alterações em andamento nas condições de competitividade de empresas, setores, regiões, países e continentes; a transformação do padrão de comércio internacional, deixando de ser eminentemente intra-setorial e intrafirmas; a "desnacionalização" dos direitos, a desterritorialização das formas institucionais e a descentralização das formas políticas do capitalismo; a uniformização e a padronização das práticas comerciais no plano mundial, a desregulamentação dos mercados de capitais, a interconexão dos sistemas financeiro e securitário em escala global, a realocação geográfica dos investimentos produtivos e a volatilidade dos investimentos especulativos; a unificação dos espaços de reprodução social, a proliferação dos movimentos imigratórios e as mudanças radicais ocorridas na divisão internacional do trabalho; e, por fim, o aparecimento de uma estrutura políticoeconômica multipolar incorporando novas fontes de cooperação e conflito tanto no movimento do capital quanto no desenvolvimento do sistema mundial (FARIA, 2004, p. 59-60).
\end{abstract}

Por conseguinte, o mundo globalizado se integra e transforma as relações até então alicerçadas na figura do Estado nacional, alterando significativamente o papel dos mesmos. Devido à globalização, estamos vivenciando uma "Crise do Estado" que significa na essência uma crise da soberania estatal, uma vez que se manifesta na transferência de parte do poder de decisão tradicionalmente reservado aos Estados, para fora de seus limites territoriais. A globalização faz com que o futuro de cada país dependa cada vez menos de suas políticas internas e se torne refém de decisões tomadas para além de seus limites territoriais, sobretudo em instituições supranacionais (por exemplo, OMC, FMI, União Europeia, etc.) ou sedes de empresas com abrangência global (FERRAJOLI, 2005, p. 109-110).

É nesse contexto atual que temos que falar da soberania nacional econômica, a qual "não supõe isolamento econômico, mas antes, pelo contrário, a modernização da economia - e da sociedade - e a ruptura de nossa situação de dependência em relação às sociedades desenvolvidas." (GRAU, 2017, p. 223).

Isso ocorre porque todos os Estados, incluindo o Estado brasileiro, tem que "navegar" 
nesse sistema financeiro global, caracterizado pela livre circulação de capitais, bem como de pessoas e informações, adaptando suas políticas, em primeiro lugar, a essa realidade mundial em que estão inseridos. (COSTA, 2004, p. 47)

Além disso, consideramos que o Estado-Nação ainda é o lócus principal para a promoção do desenvolvimento includente, frente a uma globalização que se caracteriza por formas assimétricas e desiguais que prejudicam, muitas vezes, os interesses dos países em desenvolvimento, favorecendo alguns incluídos e deixando de fora muitos excluídos. Os incluídos vivendo em um capitalismo reformado, ao passo que os excluídos ficam sujeitos a formas duras e até selvagens de capitalismo, reproduzido pela globalização, em sua forma atual, entre os países centrais (players) e periféricos, o mesmo padrão perverso de crescimento concentrado e excludente que se observa dentro das nações (SACHS, 2004, p. 64).

Nessa conjuntura, a constituição econômica do Estado brasileiro é uma instituição econômica diretiva, ou seja, dotada de um programa de política econômica. Não é possível separar a constituição econômica da constituição do Estado, pois somente há uma constituição, que é a de toda a comunidade política.

Ora, o que antes era chamado de Constituição programática, no sentido de que enuncia diretrizes, programas e fins a serem realizados pelo Estado e por toda a sociedade - é agora colocado como Constituição dirigente, que procura apontar uma direção, um norte a ser seguido.

Assim, podemos ver nossa Carta Política como expressão de um Estado "Socioambiental", cuja Constituição estabeleceu, inclusive, os objetivos a serem buscados pelo mesmo (artigo $3^{\circ}$ ), o que permite uma compreensão dinâmica da Constituição, com a possibilidade de abertura do texto constitucional para desenvolvimentos futuros (BERCOVICI, 2011, p. 208209).

Essa ação estatal visa observar o princípio da dignidade da pessoa humana, o qual ao mesmo tempo, é um dos fundamentos de nossa Constituição (art. $1^{\circ}$, III), se caracterizando como um dos núcleos dos direitos humanos (ao lado do direito à vida), bem como uma finalidade expressa da ordem econômica - "a ordem econômica tem por fim assegurar a todos existência digna", indicando a importância da busca de uma ordem econômica emancipadora (GRAU, 2017, p.191).

Destarte, é essencial se falar em planejamento, visando cumprimento, pelo nosso Estado, de seus objetivos previstos na CRFB/1988. O planejamento é um processo interativo que inclui procedimentos de baixo para cima e de cima para baixo, entendido como a capacidade de 
identificação de gargalos e de recursos ociosos capazes de superá-los, dentro do marco de um projeto nacional de longo prazo, uma visão compartilhada pela maioria dos cidadãos da nação sobre valores, a sua conversão em objetivos sociais e a inserção do seu Estado-Nação, num mundo globalizado, utilizando, inclusive, os mecanismos constitucionais possíveis (SACHS, p. 17 e 62).

E aqui se situam os instrumentos da soberania nacional, previstos no capítulo sobre a ordem econômica, que passamos a analisar no tópico a seguir.

\section{INSTRUMENTOS DA SOBERANIA ECONÔMICA NA CRFB/1988}

Convém lembrar que o artigo 170 da Constituição Federal de 1988, inserido no título da ordem econômica, elenca os princípios da ordem econômica nacional, mas não os exaure.

Aqui, se destaque, há o entendimento de que, em uma perspectiva finalista, a Constituição econômica tem por funções a ordenação da atividade econômica, a satisfação das necessidades e a direção do processo econômico em geral, bem como de reforma ou transformação estrutural. A função de ordenação da atividade econômica diz respeito à instituição da ordem pública econômica, ou seja, as regras do jogo econômico, especialmente as limitações permitidas à liberdade econômica, presentes nos arts. 170, II, III, IV, VI e IX, 172, 173, 174 § 4º 179 e 219 da CRFB/1988 (BERCOVICI, 2011, p. 209).

Quanto à satisfação das necessidades sociais, aparece de forma explícita na previsão de direitos sociais e econômicos e nos dispositivos relativos aos serviços públicos (arts. $6^{\circ}$ a $9^{\circ}, 21, \mathrm{X}$, XI e XII, 175, 178, 194, 196, 199, 201, dentre outros). A política econômica constitucional está incluída na função de direção do processo econômico geral, como nos dispositivos relativos ao desenvolvimento, pleno emprego, política monetária e distribuição de renda (artigos $3^{\circ}$, II e III, 21, VII, VIII e IX, 164, 170, VII e VIII, 176, 192, 218, dentre outros). Finalmente, a função transformadora da Constituição econômica está presente nos objetivos de nosso Estado (art. $3^{\circ}$ ), na reforma urbana e rural (artigos 182 a 191), dentre outras disposições constitucionais (BERCOVICI, 2011, p. 210).

Em suma, temos a previsão, por exemplo, da possibilidade de regulação por nosso Estado dos investimentos estrangeiros (art. 172), a propriedade de recursos minerais e os potenciais de energia hidráulica (art. 173), nos casos em que é possível a exploração direta de atividade econômica pelo Estado (art. 174), bem como o tratamento das propriedades urbana e rural (arts. 182 e 186).

Fora do aludido título, mas ante a sua natureza ligados diretamente ao exercício da

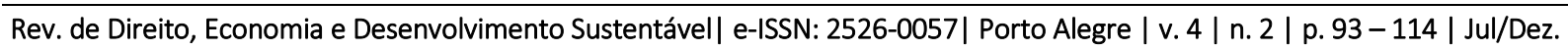


soberania econômica, temos o tratamento dado ao mercado interno (art. 219), a promoção da inovação (art. 218) e a previsão de auditoria externa da dívida pública (art. 26 do ADCT), etc.

Dentre todos estes, os que consideramos ter uma relação direta com a soberania econômica e uma maior relevância, passamos a comentar a seguir.

\subsection{Mercado Interno Como Patrimônio Nacional}

O mercado é figura essencial em um regime capitalista, o qual além de ser uma realidade econômica é também uma instituição jurídica constituída pelo Direito Positivo, o Direito posto pelo Estado moderno. (SEN, 2013, p. 32)

Que a Constituição privilegia o mercado é fato, e que é realmente necessário, com sua previsão e tratamento jurídico, pois:

É evidente que, para suas operações, os mercados como os que existem exigem mais do que o fornecimento de um espaço físico, onde passam ocorrer às compras e vendas. Exigem também o estabelecimento de normas jurídicas que regem os direitos e deveres daqueles que realizam transações nessas instalações (COASE, 2017, p. 11).

Em nossa Constituição consta a expressão "mercado interno", caracterizando o mesmo como patrimônio nacional (art. 219), o qual deve visar garantir melhores condições sociais de vida da população e a autonomia tecnológica do país, buscando um verdadeiro desenvolvimento “endógeno", ou seja, o nosso Estado deve determinar o direcionamento das atividades que compõem esse mesmo mercado interno, viabilizando a homogeneização social e a internalização dos centros de decisão econômica (BERCOVICI, 2011, p. 219-220).

Aduzir que o mercado interno é patrimônio nacional não significa que o mesmo tenha sido integrado ao domínio público, ou que o mesmo constitua um bem de uso comum do povo, como o meio ambiente. Em realidade, sua integração no patrimônio nacional se dá na medida em que nossa Constituição o toma como expressão da soberania econômica nacional. (GRAU, 2017, p. 252).

Por essa razão é que o preceito constitucional (art. 219) determina que "será incentivo de modo a viabilizar o desenvolvimento cultural e socioeconômico, o bem-estar da população e a autonomia tecnológica do País, nos termos de lei federal”. Destarte, o mercado interno é visto como um grande ativo para o desenvolvimento nacional sustentável, objetivo de nosso Estado, pois o mercado é constituído pelos agentes econômicos, dentre os quais, os trabalhadores que são, em verdade, os consumidores por excelência do que é produzido pelo mesmo mercado interno. 
Procura-se, assim, evitar restrições arbitrárias ao mecanismo de mercado, pois estes podem levar a uma redução de liberdades devido aos efeitos consequenciais da ausência de mercados. Negar às pessoas as oportunidades econômicas e as consequências favoráveis que os mercados oferecem, e sustentam, pode resultar em privações aos membros da sociedade, particularmente, os mais desfavorecidos (SEN, 2013, p. 43).

A valorização do mercado interno, consequentemente, o torna centro dinâmico do desenvolvimento brasileiro, inclusive no sentido de proporcionar garantias de melhores condições de vida para a população e a autonomia tecnológica do país, reforçando a necessidade de autonomia dos centros decisórios sobre a política econômica nacional, complementando o disposto nos artigos $3^{\circ}$, II (garantir o desenvolvimento nacional) e 170, I (a soberania nacional) da Constituição. No desempenho desse papel, o Estado, ao atuar para programar e efetuar as políticas públicas que favoreçam o desenvolvimento do mercado interno enriquece suas funções de integração, de modernização e de legitimação capitalista. (SEN, 2013, p. 41).

Prevendo esse papel ao mercado interno, nossa Constituição visa um desenvolvimento “endógeno", voltado para as necessidades de nossa sociedade, com a devida internalização dos centros de decisão econômica, a dinamização e a integração do mercado interno, para garantir uma homogeneização social com a apropriação do excedente econômico pela maior parte da população, bem como uma grande ênfase no desenvolvimento tecnológico e inovação, assunto do tópico seguinte. (BERCOVICI, 2011, p. 219-220).

\subsection{O Dever Estatal de Promoção da Teconologia e do Desenvolvimento Científico e da Inovação}

A Constituição Federal previu um dever estatal de promover e incentivar o desenvolvimento científico, a pesquisa, a capacitação científica e tecnológica e, após alteração dada pela EC-85, de 2005, a inovação, devendo ser prioridade a pesquisa científica básica e tecnológica (art. 218), inclusive na vinculação de recursos públicos nas pesquisas para solução de problemas brasileiros e do sistema produtivo (art. $218 \S 2^{\circ}$ ) - numa espécie de autodeterminação tecnológica.

Aqui temos como outro mecanismo da soberania econômica, advindo desta, a pretensão de uma autonomia tecnológica, devendo ser distintiva entre a política cientifica e a política tecnológica e inovação. Política cientifica diz respeito às atividades que pesquisam e produzem

Rev. de Direito, Economia e Desenvolvimento Sustentável| e-ISSN: 2526-0057| Porto Alegre | v. 4 | n. 2 | p. 93 - 114 | Jul/Dez. 
conhecimentos básicos e potencialmente utilizáveis, mas que não são incorporados diretamente no processo produtivo. O que inspira o texto constitucional, da regra de que ora cogito é a verificação de que, hoje, o fator determinante do crescimento econômico, parcela do desenvolvimento nacional, já que não mais é tão somente a acumulação de capital, mas também a acumulação de saber e tecnologia e inovação (GRAU, 2017, p. 261).

Já a política tecnológica abrange a geração e aquisição de tecnologia e a produção de inovação a ser utilizada em processos produtivos e sociais, além de aquisição efetiva para o país, de capacidade de decisão autônoma em tecnologia e inovação, ou seja, tratar de apropriação dos resultados científicos para fins econômicos (BERCOVICI, 2011, p. 211-212).

Nesse mesmo sentido, houve a alteração do artigo 218 da Constituição Federal pela Emenda Constitucional $n^{\circ} 85$, de 26 de fevereiro de 2015, que incluiu a inovação como preceito constitucional para nossa autodeterminação tecnológica, bem como acresceu os artigos 219-A e 219-B à Constituição, em que se possibilitou aos entes federativos "firmar instrumentos de cooperação com órgãos e entidades públicos e com entidades privadas, inclusive para o compartilhamento de recursos humanos especializados e capacidade instalada, para a execução de projetos de pesquisa, de desenvolvimento científico e tecnológico e de inovação, mediante contrapartida financeira ou não financeira assumida pelo ente beneficiário, na forma da lei”.

O que inspirou o texto constitucional original, bem como a EC - 85, ao consagrar o progresso da ciência, da tecnologia, acrescendo a inovação, visando a promoção do bem público a todos, foi a constatação de que um dos maiores fatores do desenvolvimento nacional já não é mais tão somente a acumulação de capital, mas também a acumulação de saber e de tecnologia e inovação. Hoje, se eleva a importância dos contratos do know-how, e a necessidade de reservar conhecimentos técnicos acumulados, impondo a manutenção em segredo dos novos intentos. Dai a importância da chamada "transferência de tecnologia", que somente será absorvida se houver a capacidade nacional de saber científico e tecnológico (GRAU, 2017, p. 261).

Mediante a EC 85, de 2005, também se autorizou a criação de um "Sistema Nacional de Ciência, Tecnologia e Inovação (SNCTI)" que deverá ser organizado em regime de colaboração entre entes, tanto público, como privados, com vistas a promover o desenvolvimento científico e tecnológico, e a inovação (artigo 219-B da CRFB/1988).

Regulamentando a mesma, temos a Lei 13.243, de 11 de janeiro de 2016, que alterou profundamente a Lei 10.973, de 2004, e que é um marco legal da inovação no Brasil, buscando a promoção das atividades científicas e tecnológicas como estratégicas para o desenvolvimento 
econômico e social; promoção e continuidade dos processos de desenvolvimento científico, tecnológico e de inovação, assegurados os recursos humanos, econômicos e financeiros para tal finalidade; redução das desigualdades regionais; descentralização das atividades de ciência, tecnologia e inovação em cada esfera de governo, com desconcentração em cada ente federado; a promoção da cooperação e interação entre os entes públicos, entre os setores públicos e privado e entre as empresas (art. $2^{\circ}$ da Lei 10.973, de 2004).

É previsto, também, o estímulo à atividade de inovação nas Instituições Científica, Tecnológica e de Inovação (ICTs) e nas empresas, inclusive para a atração, a constituição e a instalação de centros de pesquisa, desenvolvimento e inovação e de parques e polos tecnológicos no País; a promoção da competitividade empresarial nos mercados nacional e internacional; o incentivo à constituição de ambientes favoráveis à inovação e à transferência de tecnologia; a promoção e continuidade dos processos de formação e capacitação científica e tecnológica; o fortalecimento das capacidades operacional, científica, tecnológica e administrativa das ICTs; a atratividade dos instrumentos de fomento e de crédito; a simplificação de procedimentos para gestão de projetos de ciência, tecnologia e inovação e adoção de controle por resultados em sua avaliação e a utilização do poder de compra do Estado para fomento à inovação, com apoio, incentivo e integração dos inventores independentes às atividades das ICTs e ao sistema produtivo (art. $1^{\circ}$ da Lei 10.973, de 02 de dezembro de 2004, com redação dada pela Lei 13.243, de 2016).

Há, inclusive, incentivos fiscais federais para a inovação, mediante a Lei 11.196, de 21 de novembro de 2005, que previu como forma de incentivar a mesma: a) a exclusão do lucro líquido da base de cálculo da contribuição social sobre o lucro líquido (CSLL), do valor correspondente de até $60 \%$ da soma dos dispêndios, classificados como despesas operacionais pela legislação do IRPJ, realizados com pesquisa e desenvolvimento no ano base considerado; b) a redução de 50\% do IPI na compra de máquinas, equipamentos, aparelhos e instrumentos (nacionais ou importados) destinados à pesquisa tecnológica e desenvolvimento de inovação tecnológica, e c) a redução à zero da alíquota do imposto de renda incidente sobre as remessas ao exterior dos pagamentos de registro de manutenção de marcas e patentes (CALIENDO, 2017, p. 1038).

Todas são medidas muito importantes, pois no mundo cada vez mais se dá importância ao conhecimento, e se busca agregar mais tecnologia e, portanto, valorizar produtos e serviços. 


\subsection{Possibilidade de Regulação dos Investimentos de Capital Estrangeiro}

A Constituição, em seu artigo 172, plantou as raízes de uma regulamentação de controle - e não de regulamentação de dissuasão - dos investimentos de capital estrangeiro, incluindo a questão da remessa de lucros para o exterior. Ela não adota ordenança para o Estado hostilizar o capital estrangeiro, longe disso, mas apenas impõe ao legislador ordinário o dever de privilegiar o interesse nacional ao discipliná-lo.

Observa-se que o artigo 172 menciona o "capital estrangeiro" e não empresa estrangeira, o que possibilita diferenciação entre investimento de capital estrangeiro feito por empresas brasileiras e por empresas estrangeiras. (GRAU, 2017, p. 273).

Como possibilidade, portanto, de controle do capital estrangeiro, o previsto no artigo 172 é corolário da soberania econômica que preconiza nossa Constituição. A discussão e regulação sobre o capital estrangeiro no Brasil tem por fundamento toda a disputa em torno da remessa de lucros para o exterior, por parte das empresas estrangeiras ou suas filiais atuantes no país.

O poder econômico e, consequentemente, político, exercido pelas empresas de capital estrangeiro no Brasil, sua influência na formatação da opinião pública e sua capacidade de pressionar o Poder Público em várias questões de política econômica, sempre gerou discussões de como limitar e fiscalizar este poder, cuja fonte é externa ao nosso país.

Deste modo, a questão do controle sobre o capital estrangeiro está vinculada à transferência, ou não, dos centros de decisão sobre a atividade econômica para o exterior, incluindo o tratamento a ser dado a capitais produtivos e meramente especulativos, dando-se preferencia sempre aos primeiros e possíveis limitações aos segundos. No entanto, atualmente está regulamentada pela Lei 4.390, de 29 de agosto de 1964, na qual, é necessário dizer, o capital externo deve receber o mesmo tratamento que o capital nacional, quanto às remessas de lucros e dividendos, pagamentos de royalties e juros, desde que haja o devido registro dos recursos no Banco Central (BERCOVICI, 2011, p. 222). 


\subsection{A Propriedade dos Recursos Minerais e Potenciais de Energia Hidráulica}

Nossa Constituição dá a propriedade dos recursos minerais ${ }^{4}$, bem como dos potenciais de energia hidráulica como pertencentes à União, garantida aos concessionários apenas a propriedade do produto da lavra (artigo 173 da CRFB/1988). O controle nacional sobre os recursos minerais estratégicos, particularmente os recursos minerais e petróleo, também é decorrência da soberania econômica (BERCOVICI, 2011, p. 224).

O próprio regime de concessão, determinado no artigo $176 \S 1^{\circ}$, para a exploração dos recursos minerais, torna claro que esta atividade deve observar o interesse público, cujos atos administrativos são de competência da União, demonstrando também, claro reflexo da soberania econômica sobre esses recursos naturais. Assim, o setor privado pode explorar os recursos minerais e os potenciais hidráulicos, mediante concessão, desde que cumpridos os requisitos constitucionais e legais, com o objetivo de atender ao interesse nacional. Neste sentido, o produto da lavra é garantido ao concessionário, o que visa realçar a vinculação dos bens minerais ao interesse social, pois adquire sua propriedade quem foi devidamente habilitado pela União para tanto, não necessariamente quem descobriu a jazida ou o proprietário do solo (BERCOVICI, 2011, p. 226).

Convém lembrar a garantia ao concessionário da lavra do produto de sua exploração, sem haver sido estipulada pela Constituição qualquer restrição a ela, se concluindo que, existindo concessão de lavra regularmente outorgada, a propriedade sobre o produto da exploração é plena, ou seja, não se devem confundir as jazidas do produto que se extrai delas (GRAU, 2017, p. 295).

Cabe à União legislar sobre jazidas, minas e sobre a energia (artigo 22, XII e IV), sendo vedado aos Estados legislar sobre qualquer forma de uso de energia, salvo se autorizados, de forma supletiva, por lei complementar (artigo 22, parágrafo único).

Convém aqui lembrar que os Estados e Municípios tiveram ampliado o seu papel quanto aos recursos minerais na nossa Constituição, que transferiu a competência sobre a exploração dos serviços locais de gás canalizado (artigo $25 \S 2^{\circ}$ ) e a propriedade sobre as águas subterrâneas (artigo 26, I) para os Estados.

Além disso, também determina a proteção ao meio ambiente e o combate à poluição, inclusive, com a obrigação dos que degradarem o meio ambiental de recuperá-lo (artigo $225 \S$

\footnotetext{
${ }^{4}$ Art. 20. São bens da União: (...)

IX - os recursos minerais, inclusive os do subsolo;
}

Rev. de Direito, Economia e Desenvolvimento Sustentável| e-ISSN: 2526-0057| Porto Alegre | v. 4 | n. 2 | p. 93 - 114 | Jul/Dez. 
$2^{\circ}$ ), bem como o devido registro, acompanhamento e fiscalização das concessões de direito de pesquisa e exploração dos recursos minerais em seus territórios, como sendo competência comum da União, Estados e Municípios (artigo 23, VI e XI).

Portanto, não somente a União, mas também os demais entes federativos (Estados, Distrito Federal e Municípios) podem participar da administração dos recursos minerais, sob a direção e coordenação da União.

\section{CONSIDERAÇÕES FINAIS}

O conceito de soberania foi extremamente importante na formação dos Estados nacionais ao longo da história, como um dos fundamentos do Estado nacional surgido com a Constituição Federal de 1988, além de princípio expresso da ordem econômica, a qual deve buscar o cumprimento do objetivo de desenvolvimento sustentável preconizada por nossa Carta Política.

O princípio do desenvolvimento sustentável é figura moderna, presente em nossa Constituição, advindo dos objetivos de nosso Estado, ou seja, o aludido princípio figura como objetivo a ser perseguindo pelo Estado brasileiro.

Porém, sobretudo nas últimas três décadas, a globalização atingiu fortemente os Estados nacionais e seu poder de tomada de decisão, sendo a globalização caracterizada pela livre circulação de capitais, informações e pessoas, em âmbito internacional, a qual tem afetado esse poder de decisão, muitas vezes passado a organizações transnacionais ou empresas de alcance mundial. Como decorrência, a soberania econômica é afetada.

No entanto, ao estipular como princípio da ordem econômica preconizada pela Constituição Federal de 1988 a soberania nacional, e como a antever os vários problemas e perspectivas advindos da globalização, vimos que a CRFB/1988 previu vários instrumentos da soberania econômica, tais como o tratamento constitucional dado ao mercado interno, à promoção da ciência, tecnologia e inovação, a propriedade de recursos minerais e os potenciais de energia, a possibilidade de tratamento dos capitais e investimentos estrangeiros, como mecanismos a apontar para o exercício da soberania econômica por nosso país, portanto, um fator essencial na repercussão para o desenvolvimento sustentável, princípio norteador da atuação das políticas públicas e, em verdade, objetivo de nossa sociedade em geral. 


\section{REFERÊNCIAS}

ÁVILA, Humberto. Teoria dos Princípios - Da definição à aplicação dos princípios jurídicos. $8^{\mathrm{a}}$ edição, São Paulo: Malheiros, 2008.

BARROSO, Luís Roberto. Curso de direito constitucional contemporâneo. $3^{\text {a }}$ edição. São Paulo: Saraiva, 2011.

BERCOVICI, Gilberto. Constituição Econômica e Desenvolvimento - Uma leitura a partir da Constituição de 1988. São Paulo: Malheiros, 2005.

Paulo: Quartier Latin, 2011.

Direito Econômico do Petróleo e dos Recursos Minerais. São

BODIN, Jean. Os seis livros da República. São Paulo: Ícone, 2011.

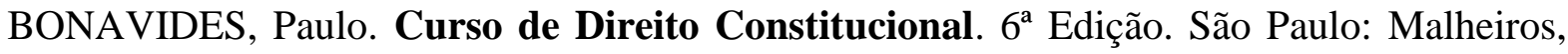
1996.

CALIENDO, Paulo. Curso de Direito Tributário. São Paulo: Saraiva, 2017.

CAnotilho, J.J. Gomes. Direito Constitucional e Teoria da Constituição. $7^{\mathrm{a}}$ edição. Coimbra: Almedina, 2003.

COASE, Ronald H. A Firma, o Mercado e o Direito. $2^{a}$ edição. São Paulo: Forense Universitária, 2017.

COSTA, José Augusto Fontoura. Globalização e Fim do Estado. In: DERANI, Cristiane. COSTA, José Augusto Fontoura (organizadores). Globalização \& Soberania. $1^{\mathrm{a}}$ ed. 2004. $4^{\mathrm{a}}$ reimpressão. Curitiba: Juruá, 2012.

DANTAS, Paulo Roberto de Figueiredo. Curso de Direito Constitucional, $1^{\text {a }}$ edição, São Paulo: Atlas, 2012.

GRAU, Eros Roberto. A Ordem Econômica na Constituição de 1988. $18^{a}$ edição, São Paulo: Malheiros, 2017.

FARIA, José Eduardo. O direito na economia globalizada. São Paulo: Malheiros Editores, 2004.

FERRAJOLI, Luigi; ATIENZA, Manuel. Democracia, Estado de Derecho y Jurisdicción en la crisis del Estado Nacional. In: Jurisdicción y Argumentación en el Estado Constitucional de Derecho. $1^{a}$ edição, México: Universidad Nacional Autónoma de México, 2005.

GONÇALVES, Alcindo. Soberania, Globalização e Direitos Humanos. In: DERANI, Cristiane. COSTA, José Augusto Fontoura (organizadores). Globalização \& Soberania. $1^{\text {a }}$ ed. Curitiba: Juruá, 2004.

HABERMAS, Jürgen. A constelação pós-nacional - Ensaios políticos. Trad. Márcio de

Rev. de Direito, Economia e Desenvolvimento Sustentável| e-ISSN: 2526-0057| Porto Alegre | v. 4 | n. 2 | p. 93 - 114 | Jul/Dez. 
Seligmann Silva. São Paulo: Littera Mundi, 2001.

KIERECZ, Marlon Silvestre. Estado do Bem-estar Social e Soberania: crise, cidadania e solidariedade. 1ª edição. Guarapuava: Edição do autor, 2015.

LAFAYETE, Josué Petter. Princípios Constitucionais da Ordem Econômica. São Paulo: Revista dos Tribunais, 2005.

LEWANDOWSKI, Enrique Ricardo. Globalização, regionalização e soberania. São Paulo: Juarez de Oliveira, 2004.

PONTES, Shara Pereira de. MASCARENHAS, Igor de Lucena. Royalties Petrolíferos: A problemática de sua Repartição no Âmbito Federativo no contexto do Desen. Sustentável. In: FEITOSA, Maria Luiza P. de A. Mayer. PEREIRA, Maria Marconiete F. Pereira (organizadores). Direito Econômico da Energia e do Desenvolvimento. $1^{\mathrm{a}}$ edição. São Paulo: Conceito Editorial, 2012.

RAYMUNDO, Lenice S. Moreira. Supranacionalidade e Intergovernabilidade: uma nova concepção de soberania estatal em face dos processos de integração na União Europeia e no Mercosul. Revista da FARN, Natal, v.2, n.2, p. 149-174 Jan./jul. 2003.

REALE, Miguel. Teoria do Direito e do Estado. $4^{\mathrm{a}}$ ed. São Paulo: Saraiva, 1984.

SACHS, Ignacy. Desenvolvimento includente, sustentável e sustentado. Rio de Janeiro: Garamond, 2004.

SARLET, Ingo Wolfgang. FENSTERSEIFER, Tiago. Princípios do Direito Ambiental. São Paulo: Saraiva, 2017.

SEN, Amarthya. Desenvolvimento como Liberdade. São Paulo: Companhia de Bolso, 2013.

SILVA, José Afonso da. Curso de Direito Constitucional Positivo. 30ª edição, São Paulo: Malheiros, 2007.

VEIGA, José Eli da. Desenvolvimento Sustentável: o desafio do século XXI. $1^{\text {a }}$ edição. Rio de Janeiro: Garamond, 2005.

Rev. de Direito, Economia e Desenvolvimento Sustentável| e-ISSN: 2526-0057| Porto Alegre | v. 4 | n. 2 | p. 93 - 114 | Jul/Dez. 